\title{
Colonialidade do poder como meio de conhecimento: em torno de seus limites e potencialidades explicativas
}

\author{
Coloniality of power as a means to knowledge: \\ its limits and explanatory potentialities
}

\section{Lucas Trindade da Silva}

\begin{abstract}
Resumo Diante da crescente importância do giro decolonial, tanto dentro como fora do contexto latino-americano, buscaremos neste artigo um retorno aos seus fundamentos, a partir de uma leitura cuidadosa dos conceitos de colonialidade do poder/racialidade e de dependência histórico-estrutural no pensamento de Aníbal Quijano. Percebemos uma relação monocausal entre a persistência da racialidade em sociedades politicamente emancipadas (explanans) e a dependência latino-americana (explanandum). Ademais, concluímos ser fundamental a utilização da contribuição decolonial como instrumento para a formação conceitual ou como meio heurístico em cooperação com outras abordagens sobre a questão racial na América Latina, como a de Carlos Hasenbalg e a de Florestan Fernandes.
\end{abstract}

Palavras-chave Decolonialidade; Colonialidade; Racialidade; Dependência.

Abstract: Given the growing importance of the decolonial turn both inside and outside the Latin American context, this article seeks to return to its roots, making a careful reading of the concepts of coloniality of power/raciality and historical-structural dependence in the thought of Aníbal Quijano. We perceive a mono-causal relationship between the persistence of raciality in politically emancipated societies (explanans) and the Latin American dependency (explanandum). Moreover, we conclude that it is fundamental to employ the decolonial contribution as a tool for conceptual formation or as a heuristic device in cooperation with other approaches of the racial issue in Latin America, such as Carlos Hasenbalg's and Florestan Fernandes'.

Keywords Decoloniality; Coloniality; Raciality; Dependence.

Visto que a exploração de classe e a opressão racial coexistem nas sociedades capitalistas multi-raciais, quando é acentuado quer a exploração de classe quer a opressão racial, o outro aspecto permanece como elemento residual e inexplicado. Os desenvolvimentos teóricos prosseguem sem se aproximarem

a Bacharel em Ciências Sociais pela Universidade Federal da Paraíba. Mestre em Sociologia pela Universidade Federal de Pernambuco. Doutorando em Sociologia na Universidade de Brasília. 
de uma explicação integrada de ambos os processos. Este é o caso da teoria das classes que enfatiza as forças de classe descuidando do antagonismo racial, e também da teoria colonial que enfatiza o racismo enquanto negligencia a dinâmica de classe (Carlos Hasenbalg, Discriminação e desigualdades raciais no Brasil, 1979).

\section{INTRODUÇÃO: ANÍBAL QUIJANO E O GIRO DECOLONIAL}

Podemos indicar como ponto de partida da discussão em torno do giro decolonial o ano de 1992, quando é fundado, inspirado no empreendimento dos Subaltern Studies, o chamado Grupo Latino-americano de Estudos Subalternos, mesmo ano da reimpressão do texto basilar de Aníbal Quijano, Colonialidad y Modernidad-Racionalidad. Como elementos convergentes entre os projetos indiano e latino-americano podemos apontar: a) a apreciação do (neo)imperialismo/(neo) colonialismo como processo básico para pensar tanto a história do centro como a das periferias do globo; b) o reconhecimento da exclusão tanto concreta como epistêmica de amplos segmentos das sociedades pós-coloniais de recente emancipação política; c) uma crítica à narrativa histórica tanto a feita na metrópole quanto a de cunho nacionalista, por reproduzir essa exclusão e contar uma história das elites; d) a proposição de uma história a contrapelo, o que em ambos os casos leva a uma crítica de caráter transdisciplinar do próprio instrumental teórico e metodológico herdado pelos autores e autoras envolvidos, todos(as), em ambas as regiões, com ampla inserção e relativa autoridade no mundo acadêmico anglo-saxão (BALLESTRIN, 2013).

Foi em torno da efetividade dessa crítica ou ruptura com o arcabouço teórico herdado, seja ele euro-americano, seja a apropriação nacionalista dos cânones teóricos das ciências sociais e da história, que se desenvolveram os impasses internos ao Grupo Latino-americano de Estudos Subalternos, os quais levaram, já em 1993, à desagregação deste e à formação, por parte dos críticos aos subalternistas no correr dos anos 90, do Grupo Modernidade/Colonialidade. É na afirmação seguida a essa desagregação que podemos identificar de forma precisa a emergência do giro decolonial. Este, ao contrário da continuidade mascarada de descontinuidade dos estudos pós-coloniais (seja nos estudos culturais, seja nas investigações subalternistas, ainda profundamente dependentes dos radicalismos teóricos pós-estruturalistas e desconstrutivistas metropolitanos), apresenta-se como "a energia que não se deixa manejar pela lógica da colonialidade, nem crê nos contos de fadas da retórica da modernidade" (MIGNOLO, 2007, p. 27; em livre 
tradução). Segundo Mignolo, que não poderia ser mais claro, "o pensamento decolonial se diferencia da teoria pós-colonial ou dos estudos pós-coloniais” por localizar-se genealogicamente não no "pós-estruturalismo francês", mas "na densa história do pensamento planetário decolonial" (2007, p. 27; em livre tradução).

Mignolo percebe uma profunda antinomia no esforço disruptivo pós-colonial que continua a lançar suas raízes em solo metropolitano, euro-americano. Não se trata, portanto, de uma casualidade, mas de um esforço central do projeto decolonial para a realização de uma genealogia do pensamento decolonial. Aqui não se está falando em canonizar Foucault e Derrida. Mignolo (2007) indica como clássicos da decolonialidade, autores como Waman Poma da Ayala, em sua Nueva Corónica y Buen Gobierno (publicado em 1616 no Peru), e Ottabah Cugoano, escravo liberto que escreveu Thoughts and Sentiments on the Evil of Slavery (publicado em Londres em 1787), os quais "abriram as portas ao pensamento outro", o primeiro "a partir da experiência e memória do Tawantinsuyu", o segundo a partir "da experiência e memória da brutal escravidão negra” na América (Mignolo, 2007, p. 29; em livre tradução). Ambos são referências do pensamento inteiramente localizado - em absoluta oposição a uma epistemologia do distanciamento, do não lugar, do "punto cero" - na própria "colonialidade do Ser, a ferida colonial" (Mignolo, 2007, p. 29; em livre tradução).

Na terminologia de Mignolo podemos perceber que, se há um esforço deliberado de se distanciar do projeto pós-colonial levado a cabo pelos subalternistas indianos (antes reconhecidos pelo Grupo Latino-americano de Estudos Subalternos), o giro decolonial continua profundamente comprometido com a gramática do texto já clássico de Aníbal Quijano, Colonialidad y Modernidad-Racionalidad. A decolonialidade aparece como o terceiro termo que se afirma a partir da negação do par inseparável modernidade/colonialidade. Conceitos como colonialidade do poder, colonialidade do saber, e racialidade permanecerão como chave na evolução do projeto decolonial, seja na tentativa de ampliação do seu campo de aplicação, seja em desenvolvimentos ulteriores: "interculturalidade e colonialidade do poder" (Walsh), "colonialidade do ser" (Maldonado-Torres), "biocolonialidade do poder" (Cajigas-Rotundo), "colonialidade linguística e epistêmica” (Garcés) para nos limitarmos às linhas de investigação apresentadas na coletânea El Giro Decolonial, de 2007 (CAStro-Gómez; Grosfoguel, 2007). Em suma, se o giro decolonial aponta para uma ruptura decisiva com o projeto pós-colonial, representado sobretudo pelos Estudos Subalternos, por outro lado, a relação com o projeto do Grupo Modernidade/Colonialidade apresenta-se como linha de continuação. 
Devido ao papel central da obra de Aníbal Quijano, principalmente seus textos publicados a partir da década de 1990, é que a tomaremos como problema. Buscaremos expor principalmente a emergência dos conceitos inseparáveis de colonialidade do poder e racialidade. Assim, daremos especial ênfase à relação entre esses conceitos e o de dependência histórico-estrutural, contribuição inteiramente original de Quijano para a teoria social latino-americana, na qual o problema da dependência passa a ser colocado nos termos causais não de relações hierárquicas entre nações ou configurações de classes internas e externas, mas na persistência de relações hierarquizadas de raça. Buscaremos salientar a importância do programa de investigação inaugurado por Quijano, destacando, no entanto, as tendências monistas - típicas de um movimento teórico que reclama aceitação e consolidação no campo - da sua tese original.

\section{COLONIALIDADE DO PODER/RACIALIDADE E DEPENDÊNCIA HISTÓRICO-ESTRUTURAL}

É no texto de 1991 Colonialidad y Modernidad-Racionalidad (Quisano, 1992) onde aparecerá pela primeira vez uma sistematização do conceito de colonialidade do poder. Se é identificável na evolução do pensamento quijaniano a passagem de uma orientação fortemente vinculada à crítica do desenvolvimentismo a partir dos marcos da teoria da dependência para, a partir dos 90, a defesa do giro decolonial, pode-se dizer que Quijano nunca deixou de ter como objetivo último tornar inteligíveis as bases do que faz da América Latina um fenômeno singular ou, para colocar em termos weberianos, uma individualidade histórica.

Pergunta-se em ambas as fases: o que explica o fracasso dos projetos de desenvolvimento nestas paragens, enquanto o pós-guerra testemunhou o êxito desses projetos em países antes não considerados centrais, como os tigres asiáticos? É a partir deste inquirimento comparativo que Quijano isolará a colonialidade do poder/racialidade como variável presente e ativa nos processos históricos latino-americanos que não se apresenta da mesma forma no contexto dos países centrais e no daqueles exitosos em seus projetos de desenvolvimento.

É mera coincidência que na escala global do planeta a esmagadora maioria das pessoas exploradas, dominadas, discriminadas, e em algumas regiões inclusive despojadas de recursos de sobrevivência, procedam das sociedades destruídas e/ou colonizadas por europeus? É mera coincidência que as regiões e/ou países da "periferia" ou "sul" correspondam, precisamente, a áreas que habitavam as sociedades destruídas e/ou colonizadas pelos europeus? É mera coincidência 
que as pessoas que descendem, parcial ou totalmente, das populações colonizadas pelos europeus sejam, em sua ampla maioria, dominadas e discriminadas seja lá onde estejam? Se não se trata - haverá quem poderia dizer que sim? nessas situações de simples coincidências históricas, não se pode fugir (eludir) das relações entre colonialidade do poder e desenvolvimento (QuiJano, 2014a, p. 205; em livre tradução; grifos colocados).

Se poder é definido como "um espaço e uma malha de relações sociais de exploração/dominação/conflito articuladas, basicamente, em função e em torno da disputa pelo controle" do "trabalho e seus produtos", da "natureza", do "sexo", da "subjetividade", e da "autoridade" (QuiJano, 2014b, p. 289; em livre tradução), a colonialidade do poder implica a articulação dessa malha "em torno da ideia de raça" (QuIJANo, 2002, p. 13; grifos colocados): naturalização de diferenças culturais, étnicas e fenotípicas.

A emergência desse padrão de poder tem como marco o ano de 1492 (a "descoberta" do Novo Mundo). Tal padrão é gestado, em suas justificativas religiosas e posteriormente científicas, no âmbito do colonialismo (pacto colonial) e mantém-se como força fundamental de estruturação das relações sociais, como forma de "classificação social básica", após a emancipação política das antigas colônias. Como claramente é colocado por Maldonado-Torres "colonialidade não significa o mesmo que colonialismo" (2007, p. 131; em livre tradução). Enquanto este diz respeito a uma "relação política e econômica, na qual a soberania de um povo está no poder de outro povo ou nação que assim se constitui em um império", a primeira "se refere a um padrão de poder que emergiu como resultado do colonialismo moderno", estrutura-se "através do mercado capitalista mundial e da ideia de raça", mas independe de uma "relação formal de poder entre dois povos ou nações" (MALDONADO-TORRES, 2007, p. 131; em livre tradução).

A intelecção da colonialidade do poder tem imediatas consequências para a teoria social e para a reflexão sobre a modernidade. Esta deixa de ser pensada como um processo endógeno ao continente europeu e que firma suas condições genéticas na Renascença italiana, na Reforma Protestante e no Iluminismo enquanto eventos fundamentais. Modernidade e colonialidade, na perspectiva de Quijano e do giro decolonial, devem ser pensados como processos de fundação recíproca e simultânea: "A outra face do mesmo processo de constituição e consolidação do Estado-nação moderno era o mundo colonizado, África e Ásia, ou dependente, como a América Latina” (QuiJANo, 2002, p. 13). 
Como bem sintetiza a imagem construída por Enrique Dussel (apud GrosfoGUEL, 2007, p. 64), não há ego cogito independente dos processos constituintes do ego conquiro. A racialização do bárbaro, a "suspeita permanente sobre a humanidade" (GROSFOGUEL, 2007, p. 64; em livre tradução) deste e a negação dessa humanidade na própria prática colonial encontram plena simetria com o ceticismo (a dúvida metódica) seguido da certeza indutivamente alcançada que funda o sujeito cartesiano (MAldonado-Torres, 2007, p. 134). De forma análoga, o ego conquiro exprime uma perversa afinidade com o ideário de razão instrumental - a concepção de natureza como objeto a ser dominado - do Novum Organum.

A "arrogância" daquele que "habla como si fuera el ojo de Dios" é a arrogância do "sujeito cuja localização geopolítica está determinada pela sua existência como colonizador/conquistador [...] como Ser imperial” (Grosfoguel, 2007, p. 64; em livre tradução). Definir a modernidade como um processo inteiramente independente da colonialidade funda precisamente a fábula da retórica da modernidade, a "hybris del punto cero" (CASTRO-Gómez, 2007, p. 83), do sujeito que anuncia a verdade para além do espaço e do tempo.

Pensar o ego cogito e o ego conquiro como processos que se conformam reciprocamente denuncia a dominação epistemológica, a colonialidade do saber que tanto é efeito como reforça a colonialidade do poder. O bárbaro - o negro, o indígena - aparece como objeto para um sujeito num sentido pleno da palavra coerção, ou seja, como objeto de trabalho e como objeto do conhecimento, expulso da condição de sujeito do conhecer. Nesta dupla determinação efetivada pela colonialidade temos a imposição: a) de uma divisão racista do trabalho, onde aquele(a) que é interpelado(a) pela racialidade é marcado(a) pela sina da escravidão, do subemprego, do trabalho precário, da informalidade; b) do eurocentrismo, isto é, a canonização do universo de conhecimento gerado (e apropriado) pelos povos de origem europeia, sua religião, sua filosofia e sua ciência, como meios unívocos para chegar à verdade e ao domínio das coisas. Para os objetivos deste artigo importa aprofundar as implicações da configuração de uma divisão racista do trabalho perpetrada pela colonialidade do poder, pois é aí onde está a base da particular teoria quijaniana do desenvolvimento desigual e combinado

A expansão do sistema-mundo capitalista dá-se pari passu à expansão e à diversificação da racialização dos povos dominados - "amarelos e azeitonados (ou oliváceos) somaram-se a brancos, índios, negros e mestiços” (QuiJANo, 2005, p. 3). A raça aqui aparece como "marco" de classificação social "dentro do qual operam as outras relações sociais, de tipo classista ou estamental" (QuiJANo, 1992, p. 438; em livre tradução). "A dominação, em consequência, não se exerce só em 
termos de classes sociais ou de estratos socioeconômicos, mas acima de tudo em termos “étnico-raciais”" (QuIJANo, 2014a, p. 208; em livre tradução), produzindo uma “distribuição racista do trabalho" (QuiJANo, 2005, p. 3; grifos colocados). Esta configura, nas colônias, uma separação rígida e profunda entre a elite branca e a massa não branca (vinculada ao trabalho manual precário, degradante e marginal ao processo de assalariamento e modernização da economia), muito mais próxima de uma estrutura de castas do que de uma estrutura de classes.

A presença/ausência desta divisão racista do trabalho será, para Quijano, decisiva na explicação da differentia specifica dos processos de formação dos estados nacionais latino-americanos, sobretudo no século XIX, em relação ao modelo clássico de formação dos estados modernos na Europa a partir do século XVII. É precisamente a ausência da dimensão racial, ou seja, a quase identificação entre a comunidade nacional e a comunidade racial, o que explica a ampla generalização e o aprofundamento das instituições democráticas e da cidadania em solo europeu, conclusão generalizável também ao caso do Japão, por exemplo.

Na América Latina, por sua vez, a presença da dimensão racial, ou melhor, da fissura racial, fez com que a comunidade nacional se identificasse com a comunidade das elites brancas, enquanto os segmentos não brancos, de cor, apareceram, ao fim do processo, como a exterioridade do recém-formado Estado-nação, como margem, como (não)sujeitos sem direitos, sem cidadania. Esse purismo de casta, essa endogenia das elites brancas, que levaram a cabo a independência política das antigas colônias, resultou numa completa indiferença ao problema da colonialidade/ racialidade no processo de transição e formação dos Estados latino-americanos. A nacionalização foi realizada sem descolonização/decolonialidade. As exceções do Cone Sul são explicadas por Quijano sobretudo pela quase total eliminação da sua população não branca.

Embasando-se em reflexões já presentes em Mariátegui, Quijano (2014a) percebe a divisão racista do trabalho como uma variável fundamental para explicar o caráter autocrático e elitista dos estados latino-americanos, pois é ela que inviabiliza a formação de "laços de solidariedade nacional" "suficientemente fortes e duradouros" "entre dominantes e dominados", e explica a forte identificação dos "dominantes "brancos" "com os interesses europeus" e a completa indiferença daqueles frente ao destino de “índios', 'negros' e 'mestiços”' (QuiJano, 2014a, p. 209; em livre tradução).

Nacionalização política sem decolonialidade, portanto, tem como resultado a situação de dependência histórico-estrutural (QuIJANo, 2005, p. 18): a aberrante aliança entre Estado independente e colonialidade social. E não há dúvida sobre 
a variável causal fundamental: "A dependência dos senhores capitalistas não provinha da subordinação nacional. Esta foi, pelo contrário, a consequência da comunidade de interesses raciais” (QuiJAno, 2005, p. 18). Tanto a subordinação nacional como a subordinação das elites periféricas às elites centrais emanam da comunidade de interesses raciais. Se ainda resta dúvida, continuemos com a palavra do próprio Quijano:

A dependência dos capitalistas senhoriais desses países tinha como consequência uma fonte inescapável: a colonialidade de seu poder levava-os a perceber seus interesses sociais como iguais aos dos outros brancos dominantes, na Europa e nos Estados Unidos. Essa mesma colonialidade do poder impedia-os, no entanto, de desenvolver realmente seus interesses sociais na mesma direção que os de seus pares europeus, isto é, transformar capital comercial (benefício igualmente produzido na escravidão, na servidão, ou na reciprocidade) em capital industrial, já que isso implicava libertar índios servos e escravos negros e transformá-los em trabalhadores assalariados. Por óbvias razões, os dominadores coloniais dos novos Estados independentes, em especial na América do Sul depois da crise de fins do século XVIII, não podiam ser nada além de sócios menores da burguesia europeia. Quando muito mais tarde foi necessário libertar os escravos, não foi para assalariá-los, mas para substituí-los por trabalhadores imigrantes de outros países, europeus e asiáticos. A eliminação da servidão dos índios é recente. Não havia nenhum interesse social comum, nenhum mercado próprio a defender, o que teria incluído o assalariado, já que nenhum mercado local era de interesse dos dominadores. Não havia, simplesmente, nenhum interesse nacional (QUIJANo, 2005, p. 18).

De forma transparente, o atrofiamento do mercado interno, a persistência de formas não assalariadas de trabalho, a predominância de um modelo primário-exportador e o débil investimento de capital num processo robusto de industrialização são explicados em última instância pela comunidade de interesses raciais dos brancos dominantes, pela vontade emanada desta comunidade de não transformar os não brancos em cidadãos e consumidores.

Quijano (1992), que em sua crítica ao materialismo histórico percebe neste uma concepção homogênea de totalidade social, ao reduzi-la à determinação em última instância da infraestrutura econômica, acaba sendo vítima da mesma tendência, colocando no lugar vazio da causa última a potência estruturante da colonialidade do poder/racialidade. Assim, não só os processos de independência 
política, abolição da escravatura, imigração europeia são explicados via colonialidade do poder/racialidade, mas também o processo de substituição de importações, "o peculiar caminho latino-americano de industrialização dependente" (QuiJANo, 2005, p. 19), obedece ao objetivo de abastecer o consumo das elites brancas, que ficou comprometido depois da crise de 30.

\begin{abstract}
A industrialização através da substituição de importações é, na América Latina, um caso revelador das implicações da colonialidade do poder. [...] A construção da nação e sobretudo do Estado-nação foram conceitualizadas e trabalhadas contra a maioria da população, neste caso representada pelos índios, negros e mestiços. A colonialidade do poder ainda exerce seu domínio, na maior parte da América Latina, contra a democracia, a cidadania, a nação e o Estado-nação moderno (QuiJano, 2005, p. 19).
\end{abstract}

Obviamente, diante da importância conferida à colonialidade do poder/ racialidade na explicação dos processos históricos latino-americanos, será essa a variável fundamental utilizada para medir o grau de consolidação do Estado-moderno no continente:

Isto quer dizer que a colonialidade do poder baseada na imposição da idéia de raça como instrumento de dominação foi sempre um fator limitante destes processos de construção do Estado-nação baseados no modelo eurocêntrico, seja em menor medida como no caso estadunidense ou de modo decisivo como na América Latina. O grau atual de limitação depende, como foi demonstrado, da proporção das raças colonizadas dentro da população total e da densidade de suas instituições sociais e culturais (QuJJANo, 2005, p. 20).

\title{
ANÍBAL QUIJANO E AS CIÊNCIAS SOCIAIS LATINO-AMERICANAS
}

É claro que a ênfase na colonialidade do poder/racialidade oculta em si uma crítica radical de qualquer resquício de defesa, seja teoricamente, seja como doxa, da ideia de democracia racial. Não há qualquer harmonia na visão quijaniana, há dominação e conflito. Por outro lado, não nos parece exagerado supor que as ideias negadas pela argumentação apaixonada de Quijano sejam também as da leitura residualista do problema racial na América Latina. Leitura esta que predominou, por exemplo, em algumas das interpretações em torno da clássica obra de Florestan Fernandes (1978 [1965]) - A Integração do Negro na Sociedade de Classes. Nessa 
obra, escreve Motta, o "preconceito de raça" aparece como "ilusório, uma vez que, bem examinado, reduz-se a um simples preconceito de classe, ou melhor, à sobrevivência de ideologias ou atitudes que, no passado, decorreram de relações de classe e subsistem no presente por força de certa inércia cultural" (МотTA, 2000, p.11). Tratando-se de um sintoma de "atraso", "inércia", "defasagem" cultural, haveria uma tendência estrutural, o próprio desenvolvimento da sociedade competitiva de classes no Brasil, a extirpá-lo. Fernandes é enquadrado num marxismo que vê o preconceito racial como mero resíduo no pós-abolição e do desenvolvimento das forças seculares da modernização.

A plausibilidade desta hipótese - sobre a dupla crítica presente no conceito de colonialidade do poder, tanto ao mito da democracia racial como às leituras residualistas da questão racial na América Latina - repousa no fato de que o giro decolonial em Quijano também representa uma ruptura com o marco da teoria da dependência. Esta conferiu privilégio analítico ao jogo de forças econômicas (troca desigual, superexploração) e geopolíticas (imperialismo, subimperialismo), em detrimento de um esforço concentrado na análise das relações raciais como fator estruturante de processos históricos de longa duração.

Se este - de um lado a defesa de democracia racial, de outro uma análise engajada com os condenados da terra, mas unilateralmente focada na questão de classe em detrimento da questão racial, esta pensada como secundária ou residual -, de fato, fosse o quadro do campo intelectual do qual emerge a ênfase na colonialidade do poder/racialidade como variável causal valorizada em última instância na explicação dos processos históricos latino-americanos, o empreendimento quijaniano após os anos 90 facilmente poderia ser classificado, na terminologia bourdieusiana (Bourdieu, 1983), como uma estratégia de subversão por parte da heterodoxia dominada, porém inserida no campo científico. Não se configuraria como uma estratégia de conservação precisamente por não buscar compromisso com as explicações ortodoxas, buscaria, ao contrário, substituir explicações canonizadas, rejeitando-as. Numa situação como esta, a inflação retórica da descoberta (racialidade) como uma panaceia explicativa, beirando o monismo, pode ser entendida em termos de uma política metodológica na qual se optou pela via revolucionária e não reformista em que todo compromisso é percebido como cooptação.

Mas não nos parece justo julgar o campo das ciências sociais das décadas imediatamente anteriores e contemporânea à emergência decolonial dessa forma. Se até hoje realmente o mito da democracia racial persiste, sobretudo como doxa, e também não se pode negar que o marxismo latino-americano (com exceção a Mariátegui e àqueles que o seguiram) e a teoria da dependência não empreen- 
deram o difícil trabalho de incorporar a dimensão da racialidade em seu universo narrativo como uma problemática fundamental, não podemos dizer que inexistiram tentativas de articular de forma não residualista as dimensões em jogo, a saber, as determinações da estrutura de classes no âmbito do mercado mundial e as determinações da colonialidade do poder/racialidade, sem cair em uma mera substituição de causas últimas ou em sucessivas reduções monistas da complexidade latino-americana.

Tomemos o próprio Florestan Fernandes. Embora de fato A Integração do Negro na Sociedade de Classes seja marcada por certa ambiguidade que possibilita uma leitura residualista da problemática da racialidade ao continuamente reiterar a classificação do preconceito de raça como um "fenômeno [sociopático] de demora cultural" (FERNANDES, 1978, v. 1, p. 460), trata-se de uma distorção imputar à obra como um todo o estigma de análise residualista da questão racial, e a Fernandes esperanças no desaparecimento espontâneo do preconceito de raça com o desenvolvimento da ordem competitiva. Esta, para Fernandes (1978, v. 1, p. 333), não elimina, por si só, "os padrões de dominação racial herdados do passado, os quais conferem o monopólio do poder aos círculos dirigentes da 'raça branca' e dão a esta a condição quase monolítica da 'raça dominante". "A 'cor' continua a operar como marca racial e como símbolo de posição social, indicando simultaneamente 'raça dependente' e 'condição social inferior"' (Fernandes, 1978, v. 1, p. 337). Para Fernandes, "[a] ordem social competitiva emergiu e expandiu-se, compactamente, como um autêntico e fechado mundo dos brancos" (Fernandes, 1978, v. 1, p. 457).

Aquele que ler de forma isolada a seguinte passagem "A única fonte dinâmica de influência corretiva irrefreável vem a ser, portanto, a própria expansão da ordem social competitiva" (FERNANDES, 1978, v. 1, p. 461) endossará a interpretação residualista da tese clássica de Fernandes. Contudo, basta ler um pouco antes na mesma página - "O desenvolvimento da ordem social competitiva encontrou um obstáculo, está sendo barrado e sofre deformações estruturais na esfera das relações raciais" - ou um pouco depois - "As tendências [democratizantes] descobertas não excluem a possibilidade de uma conciliação entre as formas de desigualdade inerente à sociedade de classes e os padrões de desigualdade racial" - para enfim rejeitar tamanha unilateralidade hermenêutica.

Vemos como em Fernandes o argumento é bem mais complexo do que a redução do preconceito de raça a preconceito contra segmentos pauperizados. Pelo contrário, uma leitura atenta d’A Integração do Negro na Sociedade de Classes evidencia a sua importância como material extremamente rico de comprovação 
empírica da força de interpelação da colonialidade do poder, internalizada pelo próprio segmento dominado. Aprofundemos.

Como sabemos, a colonialidade do poder/saber envolve: 1) a auto definição do europeu, e depois norte-americano, como sujeito da razão e da história (eurocentrismo) que implica a identificação/negação do outro como objeto definido, estável e de natureza diferenciada em relação ao sujeito; 2) a interiorização do sistema de valores dominante por parte do sujeito interpelado pela racialidade como não branco, pelo qual passa a orientar a sua ação. N’A Integração do Negro na Sociedade de Classes encontramos os dois momentos. Ao discutir sobre o problema da indiferença em relação ao futuro do negro no processo efetivo de Abolição e vitória da imigração europeia como solução para o "déficit" de força de trabalho, Fernandes (1978) deixa muito clara a presença do primeiro mecanismo da colonialidade, na medida em que o branco aparece como o "agente natural do trabalho livre" (FERnANDES, 1978, v. 1, p. 27). Enquanto "os imigrantes eram numerosos e tidos como 'poderosos e inteligentes trabalhadores", os negros "passavam a ser vistos sob um prisma que o 'escravo' desqualificava o 'liberto', como se fossem, de fato, substancialmente 'vagabundos', 'irresponsáveis' e 'inúteis”' (FERnandes, 1978, p. 73). Diante desse quadro, em que há uma naturalização de atributos que dicotomizam o branco-racional-moderno e o não branco-irracional-tradicional, reações majoritárias por parte da massa negra eram, segundo Fernandes (1978, v. 1, p. 77-85), ou a instrumentalização das condições postas pela própria hierarquia racial (como exemplifica o patrimonialismo, a submissão ao "padrinho branco"), ou a total identificação com os valores da raça dominante, exatamente o segundo mecanismo da colonialidade, a sua internalização e reprodução pela própria massa oprimida.

Isento de ambiguidade, por sua vez, é o raciocínio de Carlos Hasenbalg (1979) em seu clássico Discriminação e Desigualdades Raciais no Brasil (originalmente publicado em 1979). Embora compartilhe da leitura "residualista" d’A Integração do Negro na Sociedade de Classes, obra na qual "as relações raciais pós-abolição são conceituadas como uma área residual de relações sociais que resulta da sobrevivência de padrões 'arcaicos' de relações intergrupais, moldadas sob a escravidão”, (HASENBALG, 1979, p. 61), "principal debilidade interpretativa”, "[a]pesar da compreensiva e meticulosa dissecação das relações raciais brasileiras" (HASENBALG, 1979, p. 75) na obra clássica de Fernandes, Hasenbalg tem como fim eliminar qualquer leitura da presença do preconceito de raça como uma sobrevivência, um resíduo, um arcaísmo, assim como pretende evitar toda análise que a tome como última instância, como causa última. 
O residualismo estaria representado, para Hasenbalg, pela "perspectiva marxista ortodoxa" (C. Cox é um exemplo), que "subestima a questão da raça e do racismo" (1979, p. 109) e, consequentemente,

[...] a situação dos negros e outros grupos racialmente subordinados tende a ser explicada quase exclusivamente pela sua posição como classe trabalhadora. Preconceito e discriminação raciais são, nesta perspectiva, mecanismos manipuladores utilizados pelas classes dominantes capitalistas a fim de explorar as minorias raciais e dividir o proletariado. O racismo e o preconceito, como epifenômenos de relações econômicas, são inerentes e necessários à preservação do capitalismo (Hasenbalg, 1979, p. 109).

Em polo diametralmente oposto, ainda segundo Hasenbalg, está o que ele chama de "teoria colonial", que atacava "diretamente a tendenciosidade assimilacionista das teorias acadêmicas e a redução marxista convencional a forças de classe e exploração de classe” (Hasenbalg, 1979, p. 110). Conforme Hasenbalg,

[...] [a] novidade da teoria colonial, consiste em que ela dirige a atenção para os ganhos cumulativos (tanto econômicos quanto não econômicos) dos brancos [...] o conceito de privilégio racial sugere que, além da exploração econômica, o grupo dominante branco extrai uma certa "mais-valia” psicológica, cultural e ideológica do colonizado (HaSENBALG, 1979, p. 111).

Ambas, no entanto, apresentam limitações ao se fecharem em imputações de natureza monocausal, seja a estrutura de classes, seja a hierarquia racial. A perspectiva marxista ortodoxa deixa de explicar as situações de ausência de solidariedade entre trabalhadores brancos e negros, por exemplo, assim como negligencia o fato de que "a população negra nas antigas sociedades escravistas das Américas tem estado na retaguarda do capitalismo industrial” (HASENBALG, 1979, p. 109). A teoria colonial, por sua vez, carece "de um modelo explícito da exploração de classe e das relações entre estrutura e dominação de classes e opressão e estratificação raciais" (HASENBALG, 1979, p. 111). Temos um estado de coisas em que a ênfase numa variável implica negligenciar a outra.

É contra isso que o esforço de elaboração teórica e empírica de Hasenbalg busca afirmar-se, abrindo as portas para uma orientação multicausal e antimonista das investigações em torno da problemática em questão. 
A proposição mais geral é a de que a raça opera como um critério com uma eficácia própria no preenchimento, por não brancos, de lugares na estrutura de classes e no sistema de estratificação social. [...] A raça, como atributo socialmente elaborado, está relacionada principalmente ao aspecto subordinado da reprodução das classes sociais, isto é, a reprodução (formação - qualificação - submissão) e distribuição dos agentes. Portanto, as minorias raciais não estão fora da estrutura de classes das sociedades multi-raciais em que as relações de produção capitalista - ou quaisquer outras relações de produção no caso - através de um conjunto de práticas materiais de discriminação racial, é o determinante primário da posição dos não-brancos nas relações de produção e distribuição (HaSENBALG, 1979, p. 113-114).

\section{COLONIALIDADE DO PODER/RACIALIDADE COMO MEIO DE CONHECIMENTO}

Em relação a tal perspectiva analítica, integrada e multicausal, o giro decolonial quijaniano figura como retrocesso, na medida em que retorna a uma batalha sobre "a causa última”, estranha ao sentido do desenvolvimento científico. Não só as investigações de ordem estrutural - racialidade e (super)exploração do trabalho, por exemplo - como de ordem histórico/genética - análise dos processos de abolição, industrialização, substituição de importações, formação do mercado interno restrito, falácia do desenvolvimentismo, ampliação de direitos e cidadania, etc. - ganhariam, se despidas de um privilégio causal apriorístico' ${ }^{1}$.

Por outro lado, a correlação entre colonialidade do poder/racialidade e dependência coloca um conjunto de questões problematizadoras: como explicar o desenvolvimento estadunidense e a sua ascensão a centro hegemônico econômico-

1 Podemos também apontar, embora sem o devido aprofundamento, o retrocesso da perspectiva quijaniana e decolonial - ao conceber uma uniformidade absoluta de interesses entre as classes dominantes brancas latino-americanas e as classes dominantes dos países centrais - em relação à orientação teórico-metodológica presente, por exemplo, no clássico de Cardoso e Faletto, Dependência e Desenvolvimento na América Latina (2011). Aqui vemos uma abertura teórica à compreensão de situações concretas de desenvolvimento e dependência, sem reduzir a diversidade das singularidades a um modelo rígido e inflexível. Trata-se do avanço que significa a definição da dependência como uma "situação de ambiguidade", que "supõe um modo de ser que por sua vez depende de vinculações de subordinação ao exterior e de reorientação do comportamento social, político e econômico em função de “interesses nacionais' [...] [A] análise da dependência significa que não se deve considerá-la como uma 'variável externa', mas que é possível analisá-la a partir da configuração do sistema de relações entre as diferentes classes sociais no âmbito mesmo das nações dependentes" (CARDOSO; FALETTO, 2011, p. 44; grifos colocados). Numa situação marcada inerentemente pela ambiguidade, não se pode falar, como em nenhuma outra situação histórica, com tamanha generalidade sobre os interesses da classe dominante branca. Seja no centro, seja na periferia, o bloco do poder é um compromisso conflituoso entre distintas frações de classes com capacidades diferenciadas de exercício da hegemonia. 
-político-militar diante da força da racialidade ou do padrão colonial de relação inter-racial naquele país? Será de fato justo caracterizar os países asiáticos que passaram por processos recentes de desenvolvimento como livres da chaga da colonialidade do poder/racialidade?

Fora de dúvida, no entanto, é o potencial heurístico dos conceitos quijanianos e suas relações. Se a teoria colonial (provavelmente representada por autores como Memmi, Césaire, Fanon) mencionada por Hasenbalg já colocava de forma clara a problemática racial, esta só ganhou em clareza com a noção de colonialidade do poder/racialidade em Quijano. O axioma sobre a relação necessária Modernidade/Colonialidade e os insights quijanianos sobre a influência da racialidade em processos de (sub)desenvolvimento nos parecem fundamentais se tomados como um ponto de partida para a pesquisa empírica e para a aproximação à realidade concreta.

Enfatizar o potencial heurístico de elaborações conceituais e propor o uso de conceitos explicativos como meios de conhecimento implica, na terminologia das contribuições epistemológicas e metodológicas de Max Weber (1993; 1995) para as ciências sociais, extirpar toda tendência emanatista ou substancialista dessas próprias elaborações intelectuais, ou seja, rejeitar toda leitura desses conceitos como a expressão da essência última da realidade investigada ou como idênticas ao real.

O intuito não é de propor, como o fez o próprio Weber em relação a Marx, por exemplo, uma leitura típico-ideal das contribuições quijanianas. Isso porque, estrito senso, afirmar uma metodologia orientada por tipos ideais é também um compromisso com uma epistemologia nominalista e antirrealista, conjugado à aceitação do racionalismo interpretativo via individualismo metodológico como meio heurístico para a compreensão da ação social. Além disso, a lógica da formação típico-ideal é por demais formal, por demais estática, estranha ao caráter processual e contraditório da realidade efetiva.

A argumentação weberiana, em contenda com o historicismo e com o naturalismo do seu tempo, nos é útil aqui unicamente em sua contínua insistência na afirmação de uma analítica do conceito nas ciências sociais, enquanto consciência permanente: da não identidade das elaborações intelectuais em relação à própria realidade investigada (que pode ser apropriada sem necessariamente cair num idealismo ou recair na antinomia fenômeno/númeno); da particularidade dos interesses (ideológicos, valorativos) que nos levam a ter interesse e a problematizar um fragmento da complexidade-mundo (sem cair num relativismo perspectivista); do imperativo de inquirir continuamente, empírica e logicamente, sobre a vali- 
dade dos constructos teóricos e conceituais acumulados na história da ciência. Trata-se, em uma frase, de tornar o pensamento subordinado à realidade em sua irredutibilidade processual. É neste sentido fraco, despido do seu racionalismo e do seu individualismo metodológico, que nos interessa a formulação weberiana do tipo ideal, a saber, como constructo intelectual que "não interessa como fim, mas única e exclusivamente como meio de conhecimento" (WEBER, 1993, p. 139; grifos colocados).

Trata-se de um quadro de pensamento, não da realidade histórica, e muito menos da realidade "autêntica"; não serve de esquema em que se possa incluir a realidade à maneira de exemplar. Tem, antes, o significado de um conceito-limite, puramente ideal, em relação ao qual se mede a realidade a fim de esclarecer o conteúdo empírico de alguns dos seus elementos importantes, e com o qual esta é comparada (WEBER, 1993, p. 140).

Nessa acepção, teorias e conceitos devem ser apropriados como instrumentos, como meios de aproximação à realidade dos processos históricos, como orientações cognitivas na operação de imputações causais. "Não se trata de saber a que fórmula se deve subordinar o fenômeno a título de exemplar, mas sim a que constelação deve ser imputado como resultado" (WEBER, 1993, p. 129).

Tomado dessa forma, o conceito de colonialidade do poder/racialidade, mais particularmente a intelecção da sua importância na conformação de processos de (sub)desenvolvimento e dependência na América Latina e alhures, funciona não como uma lei genérica sob a qual devem ser subordinadas as mais diversas formações históricas e nacionais de passado colonial, mas como um meio de conhecimento - ao lado da imputação daqueles processos ao conflito de classes no âmbito do mercado mundial e/ou a fenômenos de ordem geopolítica -, de maior ou menor importância na explicação de processos históricos concretos, num horizonte de pesquisa necessariamente multicausal.

\section{REFERÊNCIAS BIBLIOGRÁFICAS}

BALLESTRIN, Luciana. América Latina e o giro decolonial. Revista Brasileira de Ciência Política, Brasília, n. 11, p. 89-117, 2013.

BOURDIEU, Pierre. "Gostos de classe e estilos de vida”. In: oRTIz, Renato. (Org.). Pierre Bourdieu: Sociologia. São Paulo: Ática, 1983, p. 46-81. 
CASTRO-GÓMEZ, Santiago; GROSFOGUEL, Ramón. (Org.). El giro decolonial: reflexiones para una diversidad epistémica más allá del capitalismo global. Bogotá: Siglo de Hombre Editores, 2007.

CASTRO-GÓMEZ, Santiago. "Decolonizar la universidad: la hybris del punto cero y el diálogo de saberes”. In: CASTRO-GÓMEZ, Santiago; GROSFOGUEL, Rámon (Org.). El giro decolonial: reflexiones para una diversidad epistémica más allá del capitalismo global. Bogotá: Siglo de Hombre Editores, 2007, p. 79-91.

CARDOSO, Fernando Henrique; FALETTO, Enzo. Dependência e Desenvolvimento na América Latina. Rio de Janeiro: Civilização Brasileira, 2011.

FERNANDES, Florestan. A integração do negro na sociedade de classes. São Paulo: Ática, 1978. v. 1.

GROSFOGUEL, Ramón. "Descolonizando los universalismos occidentales: el pluriversalismo transmoderno decolonial desde Aimé Césaire hasta los zapatistas". In: CASTRO-GÓMEZ, Santiago; GROSFOGUEL, Ramón (Org.). El giro decolonial: reflexiones para una diversidad epistémica más allá del capitalismo global. Bogotá: Siglo de Hombre Editores, 2007, p. 63-77.

HASENBALG, Carlos. Discriminação e desigualdades raciais no Brasil. Rio de Janeiro: Edições Graal, 1979.

MALDONADO-TORRES, Nelson. "Sobre la colonialidad del ser: contribuciones al desarrollo de un concepto”. In: CASTRO-GÓMEZ, Santiago; GROSFOGUEL, Ramón (Org.). El giro decolonial: reflexiones para una diversidad epistémica más allá del capitalismo global. Bogotá: Siglo de Hombre Editores, 2007, p. 127-167.

MIGNOLO, Walter. "El pensamiento decolonial: desprendimiento y abertura". In: CASTRO-GÓMEZ, Santiago; GROSFOGUEL, Ramón. (Org.). El giro decolonial: reflexiones para una diversidad epistémica más allá del capitalismo global. Bogotá: Siglo de Hombre Editores, 2007, p. 25-45.

MOTTA, Roberto. Paradigmas de interpretação das relações raciais no Brasil. Estudos afro-asiáticos, Rio de Janeiro, n. 38, p. 113-133, 2000.

QUIJANO, Aníbal. “Colonialidad y Modernidad-Racionalidade”. In: BONILLA, Heraclio. Los Conquistados: 1492 y la población indígena de las Américas. Bogotá: Tercer Mundo, 1992, p. 437-447.

El fantasma del desarrollo en América Latina. Rev. Venez. de Econ.y Ciencias Sociales, v. 6, n. 2, p. 73-90, 2000.

. Colonialidade, poder, globalização e democracia. Novos rumos, n. 37, p. 4-28, 2002.

"Colonialidade do poder, eurocentrismo e América Latina". In: LANDER, Edgardo. (Org.). A colonialidade do saber: eurocentrismo e ciências sociais. 
Perspectivas latino-americanas. Colección Sur Sur. Buenos Aires: CLACSO, 2005, p. 107-130. Disponível em: <http://bibliotecavirtual.clacso.org.ar/ar/libros/lander/ pt/Quijano.rtf>. Acesso em: 20/10/2014.

“América Latina en la economía mundial”. In: CLÍMACO, Danilo Assis (Org.) Cuestiones y Horizontes: de la dependencia historico-estrutural a la colonialidad/ descolonialidad del poder. Buenos Aires: CLACSO, 2014a, p. 199-214. Disponível em: $<$ http://biblioteca.clacso.edu.ar/clacso/se/20140424014720/Cuestionesy horizontes. pdf $>$. Acesso em: 28/04/2014.

. “Colonialidad del poder y Claficiación Social”. In: CLÍMACO, Danilo Assis (Org.) Cuestiones y Horizontes: de la dependencia historico-estrutural a la colonialidad/descolonialidad del poder. Buenos Aires: CLACSO, 2014b, p. 285-327. Disponível em: <http://biblioteca.clacso.edu.ar/clacso/se/20140424014720/ Cuestionesy horizontes.pdf $>$. Acesso em: 28/04/2014.

WEBER, Max. Metodologia das ciências sociais (parte I). São Paulo: Cortez, 1993. . Metodologia das ciências sociais (parte II). São Paulo: Cortez, 1995.

Recebido para publicação em: 12/05/2015. Aceito para publicação em 11/08/2015. 